\title{
Effect of anogenital distance on stress urinary incontinence
}

\author{
Murat Ekmez ${ }^{1 *}$ (10 and Firat Ekmez ${ }^{2}$
}

\begin{abstract}
Background: To clarify the effect of anogenital distance (AGD) on stress urinary incontinence (SUI) in female patients.

Methods: Charts of patients who admitted to urogynecology polyclinic between December 2020 and February 2021 were analyzed retrospectively. The AGD parameters including anogenital distance from the anus to the clitoris $\left(A G D_{A C}\right)$, anogenital distance from the anus to the fourchette $\left(A G D_{A F}\right)$ and genital hiatus $(G H)$ were measured. To identify effect of ADG parameters on SUI, patients were divided into the two subgroups (patients with SUI and without SUI). Demographic characteristics of patients and perineal anatomy measurement were compared between groups.

Results: Totally, 256 female patients met study inclusion criteria. In comparison of patients with and without SUI, demonstrated that age, weight, height, and BMI were similar between groups $(p=0.200, p=0.455, p=0.131$, and $p=0.215$, respectively). The AGD $\mathrm{AF}_{\mathrm{AF}}$ was measured $22.6 \mathrm{~mm}$ in patients with SUI and $25.5 \mathrm{~mm}$ in patients without SUI $(p=0.014)$. In contrast, $A_{G D}$ AC was significantly longer in patients with SUI $(81.1 \mathrm{~mm}$ vs. $72.2 \mathrm{~mm}, p=0.001)$. Also, $\mathrm{GH}$ was significantly longer in patients with SUI $(p=0.016)$. Multivariate logistic regression analysis revealed that one $\mathrm{mm}$ increment in $\mathrm{AGD}_{\mathrm{AC}}$ and $\mathrm{GH}$, is associated with 1.108- and 1.038-fold time of SUI development risk, respectively $(p=0.001$ and $p=0.004)$. In contrast, decrease in $\mathrm{AGD}_{\mathrm{AF}}$ is resulted with significantly higher risk for $\mathrm{SUI}(p=0.001)$.

Conclusion: The present study demonstrated that shorter $A G D_{A F}$ and longer $A G D_{A C}$ and $G H$ were resulted with significantly higher incidence of SUI. Considering the ease and non-invasiveness of anogenital distance measurement, an important implication of the results of current study is that it is a measurement that can be easily performed during routine gynecological and obstetric examinations as a suitable tool for use in the prediction of women who will develop stress incontinence in the future.
\end{abstract}

Keywords: Anogenital distance, Genital hiatus, Stress urinary incontinence, Female, Reproductive age

\section{Background}

Stress urinary incontinence (SUI) is described as any involuntary loss of urine with increased abdominal pressure such as coughing, sneezing or physical exercise, according to the International Continence Society [1]. Incidence of SUI is very high in female population and Jha et al. demonstrated that quarter of women experienced with life quality deterioration due to SUI in their lifespan [2]. Factors affecting on SUI are still under

\footnotetext{
*Correspondence: muratekmez@hotmail.com

${ }^{1}$ Department of Gynecology and Obstetrics, Haseki Training

and Research Hospital, Millet Street, Fatih, Istanbul, Turkey

Full list of author information is available at the end of the article
}

investigation and previous reports tried to identify reasons for SUI including age, body mass index (BMI), number of births, previous gynecological surgery history, and perineal anatomic properties [3].

Effects of perineal anatomy characteristics on SUI is one of the hottest topic in urogynecology. Shin et al. investigated the relation between urethral length and SUI, and authors claimed that patients with SUI had a significantly shorter urethral length than in patients without SUI [4]. In another study, Athanasopoulos and colleagues evaluated the correlation between perineal measurement parameters (perineal body length, fourchette-coccyx distance, anal-coccyx length) and SUI in women; however, authors found perineal measurement 
parameters had no effect on SUI [5]. Distance between the anus and external genital, also called anogenital distance (AGD), is dimorphic sexual characteristic, and AGD is accepted as a sign of androgen exposure during prenatal period [6]. Sanchez-Ferrer et al. analyzed the relation between AGD parameters and pelvic organ prolopsus, and longer genital hiatus length and anoclitoral distance found as predictive factors for pelvic organ prolopsus. However, Sanchez-Ferrer and colleagues did not focus on AGD parameters' effects on SUI [7].

Although previous studies analyzed the effect of AGD on fertility, premature ejaculation, pelvic organ prolapses, and prostate cancer, none of study has investigated the effect of AGD on SUI. In present study, we aim to clarify the effect of AGD on SUI in female patients.

\section{Methods}

Charts of patients who admitted to urogynecology polyclinic between December 2020 and February 2021, were analyzed retrospectively. Ethical approval was achieved from local ethics committee, and informed consent for participate to study was signed for all patients. Detailed medical history was obtained and patients' characteristics including age, weight, height, BMI, ASA (American society of anesthesiologists) score, and number of parity were recorded. Physical examination was performed for all patients, and AGD parameters including anogenital distance from the anus to the clitoris $\left(\mathrm{AGD}_{\mathrm{AC}}\right)$, anogenital distance from the anus to the fourchette $\left(\mathrm{AGD}_{\mathrm{AF}}\right)$ and genital hiatus $(\mathrm{GH})$ were measured. Also, all patients were evaluated according to Pelvic Organ Prolapse Quantifications System (POP-Q). To diagnose SUI, all patients did Valsalva maneuver with empty bladder, then $300 \mathrm{cc}$ of fluid is injected into the bladder and Valsalva maneuver performed again. Patients with urge and/or mixed incontinence type, severe mental inability, severe neurological disease, neurogenic bladder and refusal to content, were excluded from the study. Other exclusion criteria were being $<18$ years old, history of stress incontinence surgery, presence of gynecological tumor, rectal disease and active infection in anogenital area.

\subsection{Anogenital distance measures}

All AGD parameters were measured in lithotomy position with $45^{\circ}$ angle of thighs. Stainless steel digital caliper (Supplier: VWR ${ }^{\circledR}$ International, LLC, West Chester, PA, USA) was used for all measurements. Distance between the upper edge of the anus and clitoris was accepted as $\mathrm{AGD}_{\mathrm{AC}}$, and distance from upper edge of the anus to posterior fourchette was accepted as $\mathrm{AGD}_{\mathrm{AF}}$, retrospectively. According to POP-Q, genital hiatus length defined from urethral meatus center to the edge of the perineum nucleus or posterior midline of hymen. To achieve more accurate outcomes, each AGD parameters were measured twice by two physician.

To identify effect of ADG parameters on SUI, patients were divided into the two subgroups (patients with SUI and without SUI). Demographic characteristics of patients and perineal anatomy measurement were compared between groups.

\subsection{Data analysis}

The Statistical Package for the Social Sciences version 25 (SPSS IBM Corp., Armonk, NY, USA) program was used. Normality of distribution of the variables was checked by Shapiro-Wilk test and Q-Q plots. Independent Student's $t$ test was used for comparison of the normally distributed variable between the groups, and Mann-Whitney $U$ test was used for non-normally distributed data. Quantitative data are showed as mean \pm standard deviation values. Categorical variables were grouped and compared using the $\chi^{2}$ test or Fisher's exact test. Binary logistic regression analysis was used for evaluate to parameters of anogenital distance in terms of incontinence risk. The data were analyzed at a $95 \%$ confidence level and P value of less than 0.05 was accepted as statistically significant.

\section{Results}

Totally, 256 female patients with mean age 36.9 years, met study inclusion criteria. The mean weight and height of patients were $74.9 \mathrm{~kg}$ and $162.2 \mathrm{~cm}$, respectively. The mean BMI of study population was $28.5 \mathrm{~kg} / \mathrm{m}^{2}$. Only, 26 (10.2\%) patients were nulliparous. The mean $\mathrm{AGD}_{\mathrm{AF}}$ and $\mathrm{AGF}_{\mathrm{AC}}$, were measured $24.9 \mathrm{~mm}$ and $73.8 \mathrm{~mm}$, respectively. The distance of $\mathrm{GH}$ was $22.7 \mathrm{~mm}$. According to POP-Q test, 143 patients were categorized as stage 0 , and 77 patients and 36 patients were classified into stage 1 and stage 2, respectively. Demographic data of patients are summarized in (Table 1).

In comparison of patients with and without SUI, demonstrated that age, weight, height, BMI, and ASA score were similar between groups $(p=0.200, p=0.455$, $p=0.131, p=0.215$, and $p=0.867$, respectively). Also, nulliparous rate was not significant different $(10.9 \%$ vs. $10.0 \%, p=0.964)$. The $\mathrm{AGD}_{\mathrm{AF}}$ was measured $22.6 \mathrm{~mm}$ in patients with SUI and $25.5 \mathrm{~mm}$ in patients without SUI $(p=0.014)$. In contrast, $\mathrm{AGD}_{\mathrm{AC}}$ was significantly longer in patients with SUI $(81.1 \mathrm{~mm}$ vs. $72.2 \mathrm{~mm}, p=0.001)$. Also, GH was significantly longer in patients with SUI in comparison of patients without SUI $(P=0.016)$. The POP-Q stages were comparable between groups $(p=0.478)$ (Table 2).

Multivariate logistic regression analysis revealed that one $\mathrm{mm}$ increment in $\mathrm{AGD}_{\mathrm{AC}}$ and $\mathrm{GH}$, is associated with 1.108- and 1.038-fold time of SUI development risk, respectively $(p=0.001$ and $p=0.004)$. In contrast, 
Table 1 Demographics data of all patients

\begin{tabular}{|c|c|}
\hline & $n: 256$ \\
\hline Age (years)* & $36.9 \pm 9.3$ \\
\hline Weight (kg)* & $74.9 \pm 15.9$ \\
\hline Height $(\mathrm{cm})^{*}$ & $162.2 \pm 5.4$ \\
\hline BMI $\left(\mathrm{kg} / \mathrm{m}^{2}\right)^{*}$ & $28.5 \pm 5.8$ \\
\hline ASA score & $1.2 \pm 0.4$ \\
\hline \multicolumn{2}{|l|}{ Parity n;(\%) } \\
\hline Nulliparous & $26(10.2 \%)$ \\
\hline Parity $\geq 1$ & 230 (89.8\%) \\
\hline $\mathrm{AGD}_{\mathrm{AF}}(\mathrm{mm})^{*}$ & $24.9 \pm 5.9$ \\
\hline $\mathrm{AGD}_{\mathrm{AC}}(\mathrm{mm})^{*}$ & $73.8 \pm 12.0$ \\
\hline $\mathrm{GH}(\mathrm{mm})^{*}$ & $22.7 \pm 8.0$ \\
\hline \multicolumn{2}{|l|}{ POP Q stage } \\
\hline 0 & 143 (55.9\%) \\
\hline 1 & 77 (30.1\%) \\
\hline 2 & 36 (14.0\%) \\
\hline
\end{tabular}

ASA American society of anesthesiologists, $A G D_{A C}$ Anogenital distance from the anus to the clitoris, $A G D_{A F}$ Anogenital distance from the anus to the fourchette, $B M I$ Body mass index, GH Genital hiatus, $P O P Q$ Pelvic Organ Prolapse Quantifications System

Table 2 Comparison of patient data by stress urinary incontinence status

\begin{tabular}{|c|c|c|c|}
\hline & $\begin{array}{l}\text { Presence of SUI } \\
(n: 46)\end{array}$ & $\begin{array}{l}\text { Absence of SUI } \\
(n: 210)\end{array}$ & $p$ value \\
\hline Age (years)* & $38.4 \pm 9.0$ & $36.6 \pm 9.3$ & 0.200 \\
\hline Weight $(\mathrm{kg})^{*}$ & $78.1 \pm 16.7$ & $74.2 \pm 15.6$ & 0.455 \\
\hline Height $(\mathrm{cm})^{*}$ & $162.9 \pm 4.6$ & $162.0 \pm 5.8$ & 0.131 \\
\hline BMI $\left(\mathrm{kg} / \mathrm{m}^{2}\right)^{*}$ & $29.4 \pm 6.3$ & $28.3 \pm 5.6$ & 0.215 \\
\hline ASA score & $1.2 \pm 0.4$ & $1.2 \pm 0.4$ & 0.867 \\
\hline Parity n;(\%) & & & 0.964 \\
\hline Nulliparous & $5(10.9 \%)$ & $21(10.0 \%)$ & \\
\hline Parity $\geq 1$ & 41 (89.1\%) & 189 (90.0\%) & \\
\hline $\mathrm{AGD}_{\mathrm{AF}}(\mathrm{mm})^{*}$ & $22.6 \pm 7.1$ & $25.5 \pm 5.5$ & 0.014 \\
\hline $\mathrm{AGD}_{\mathrm{AC}}(\mathrm{mm})^{*}$ & $81.1 \pm 9.5$ & $72.2 \pm 11.9$ & 0.001 \\
\hline $\mathrm{GH}(\mathrm{mm})^{*}$ & $24.4 \pm 6.1$ & $22.2 \pm 8.3$ & 0.016 \\
\hline POP-Q stage & & & 0.478 \\
\hline 0 & $30(65.2 \%)$ & $134(63.8 \%)$ & \\
\hline 1 & $12(26.1 \%)$ & 44 (20.9\%) & \\
\hline 2 & $4(8.9 \%)$ & $32(15.2 \%)$ & \\
\hline
\end{tabular}

ASA American society of anesthesiologists, $A G D_{A C}$ Anogenital distance from the anus to the clitoris, $A G D_{A F}$ Anogenital distance from the anus to the fourchette, $B M I$ Body mass index, GH Genital hiatus, POP Q Pelvic Organ Prolapse Quantifications System, SUI Stress urinary incontinence

decrease in $\mathrm{AGD}_{\mathrm{AF}}$ is resulted with significantly higher risk for SUI $(p=0.001)$ (Table 3). The ROC analyses showed that the $A U C$ values of $A G D_{A C}, A G D_{A F}$ and $\mathrm{GH}$ for predicting SUI were 0.706, 0.692, and 0.671,
Table 3 Logistic regression analysis of anogenital distance parameters in terms of incontinence risk

\begin{tabular}{llll}
\hline & Odds ratio & \%95 Cl & P value \\
\hline $\mathrm{AGD}_{\mathrm{AF}}(\mathrm{mm})$ & 0.833 & $0.772-0.898$ & $\mathbf{0 . 0 0 1}$ \\
$\mathrm{AGD}_{\mathrm{AC}}(\mathrm{mm})$ & 1.108 & $1.069-1.148$ & $\mathbf{0 . 0 0 1}$ \\
$\mathrm{GH}(\mathrm{mm})$ & 1.038 & $1.008-1.045$ & $\mathbf{0 . 0 0 4}$ \\
\hline
\end{tabular}

$A G D_{A C}$ Anogenital distance from the anus to the clitoris, $A G D_{A F}$ Anogenital distance from the anus to the fourchette, $G H$ Genital hiatus

respectively. ( $p=0.001, p=0.003$ and $p=0.005$, respectively) (Fig. 1).

\section{Discussion}

The AGD is simple and non-invasive anthropometric measurement, and the length of AGD is twice as longer in males than in females. Previous animal and human studies have demonstrated that AGD is an indirect sign of androgen exposure during prenatal period which affect the length of AGD in both sex. However, androgen exposure during prenatal period has different effects on both genders, resulted with shorter AGD in male and longer AGD in female $[8,9]$. In male, shorter AGD length was found a predictive factor for atrophic testes, cryptorchidism, hypospadias, infertility, and lower testosterone hormone levels [10]. Similarly, longer AGD was detected in hormone related diseases such as endometriosis, congenital adrenal hyperplasia, and polycystic over syndrome [11]. First time, we analyze the AGD parameters effect on SUI, and we found longer $\mathrm{AGD}_{\mathrm{AC}}$ and $\mathrm{GH}$, and shorter $\mathrm{AGD}_{\mathrm{AF}}$ was predictive factors for $\mathrm{SUI}(p=0.001$, $p=0.016$ and $p=0.014$, respectively).

The effect of $\mathrm{AGD}_{\mathrm{AF}}$ and $\mathrm{AGD}_{\mathrm{AC}}$ on clinic outcomes controversial issue and still under investigation. Bump el al. claimed subcutaneous structures including muscle and connective tissues, and position of hymen have an effect of $\mathrm{AGD}_{\mathrm{AF}}$ and $\mathrm{AGD}_{\mathrm{AC}}$ measurement [12]. In addition, Swan and colleagues stated uncertain anatomical landmarks make measure $\mathrm{AGD}_{\mathrm{AF}}$ more difficult [13]. Despite the negativities, Hernandez et al. found significantly correlation between longer $\mathrm{AGD}_{\mathrm{AC}}$ and polycystic over syndrome [14]. On the other hand, longer $\mathrm{AGD}_{\mathrm{AF}}$ was defined as a predictive factor for higher ovarian follicle number, presence of endometriomas, and deep endometriosis [15]. Moreover, longer $\mathrm{AGD}_{\mathrm{AC}}$ and shorter $\mathrm{AGD}_{\mathrm{AF}}$, were found in patients with pelvic organ prolapses [7]. In present study, we determined significantly longer $\mathrm{AGD}_{\mathrm{AC}}$ and shorter $\mathrm{AGD}_{\mathrm{AF}}$ distance in patients with SUI.

Previous reports investigated effect of GH length on the pelvic floor deficiency. Vakili and colleagues analyze the correlation between $\mathrm{GH}$ parameters and strength of 

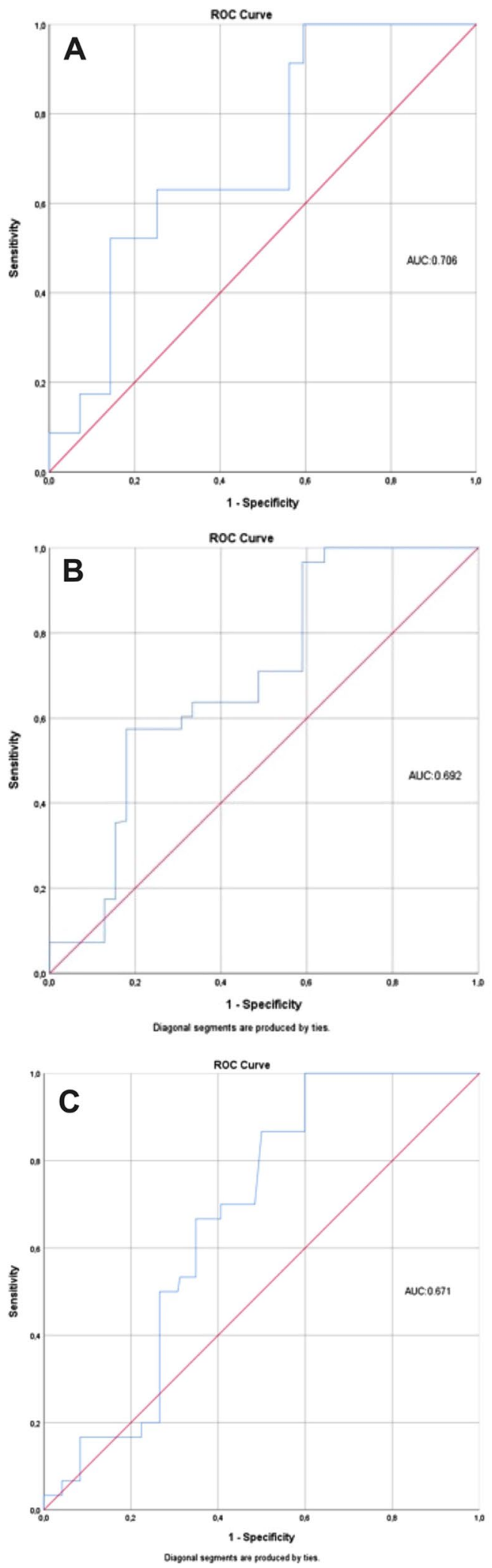

Fig. 1 Receiver operating characteristics curve analysis of $A G D_{A C}$ a, $A G D_{A F} \mathbf{b}, G H \mathbf{c}$ for predicting stress urinary incontinence levator ani muscle contractions in patients with failed prolapse surgery, and authors concluded longer GH caused increment in surgical failure in early postoperative period of prolapse surgery [16]. In another study, Lowder et al. tried to identify predictive factors for pelvic organ prolapses, and authors stated that longer $\mathrm{GH}$ distance was related with vaginal support loss and higher pelvic organ prolapses rate [17]. To our knowledge, pelvic floor deficiency is common in patients with SUI. In accordance with this hypothesis, we found significantly longer GH distance in patients with SUI, in comparison of patients without SUI.

Although, this paper is the first study focused on relation between AGD parameters and SUI, we are aware of the limitations caused by the retrospective nature of study and limited patients' number. In addition, we only investigated the AGD-SUI relationship, we did not evaluate the effect of AGD on SUI medical and/or surgical treatments' outcomes, which may be subject of another study. Body structure including AGD parameters may be affected by genetic differences and races, and our study was performed in one tertiary academic center. We believe further studies in different races contribute to understand the relationship between AGD parameters and SUI.

\section{Study limitations}

Some limitations of this study were a small sample size as well as the fact that it was a single center study. Larger multicenter studies are required to establish the true effects of AGD on SUI.

\section{Conclusion}

Present study demonstrated that shorter AGDAF and longer AGDAC distances were resulted with significantly higher incidence of SUI. Additionally, our study found that one $\mathrm{mm}$ increment in $\mathrm{GH}$ length was associated with 1.038 -fold time of SUI development risk. This study is the first to analyze relation between AGD parameters and SUI, our study findings should be supported by prospective studies with more sample size. An important aspect of the results of this study is that, considering the ease and non-invasiveness of anogenital distance measurement, it is a measurement that can be easily performed during routine gynecological and obstetric examinations, and that it is suitable for use in the prediction of women who will develop stress incontinence in the future. Although it is obvious that the introduction of anogenital distance measurement into routine clinical practice will be beneficial, it should be supported by the data of studies with long-term follow-up in order to form a general consensus and to be beneficial for women. 


\section{Abbreviations}

SUI: Stress urinary incontinence; BMI: Body mass index; AGD: Anogenital distance; ASA: American society of anesthesiologists; AGD $_{A C}$ : Anogenital distance from the anus to the clitoris; $A G D_{A F}$ : Anogenital distance from the anus to the fourchette; GH: Genital hiatus.

\section{Authors' contributions}

M.E. and F.E. involved in surgical and medical practices; M.E. and F.E. participated in concept; M.E. and F.E. participated in design; M.E. and F.E. involved in data collection or processing; M.E. and F.E. participated in analysis or interpretation; M.E. and F.E. involved in literature search; M.E. and F.E. involved in writing. All authors read and approved the final manuscript.

\section{Funding}

The authors declare and accept that they did not receive any specific grant from funding agencies.

\section{Availability of data and materials}

The datasets used and/or analyzed during the current study are available from the corresponding author on reasonable request.

\section{Declarations}

\section{Ethics approval and consent to participate}

This study was approved by the Haseki Training and Research Hospital (protocol number:17/2020). Informed written consent was obtained from all patients.

\section{Consent for publication}

Not Applicable.

\section{Competing interests}

The authors declare that they have no known competing interests.

\section{Author details}

${ }^{1}$ Department of Gynecology and Obstetrics, Haseki Training and Research Hospital, Millet Street, Fatih, Istanbul, Turkey. ${ }^{2}$ Department of Gynecology and Obstetrics, Private Clinic, Silopi, Sırnak, Turkey.

Received: 30 May 2021 Accepted: 5 October 2021

Published online: 18 October 2021

\section{References}

1. Abrams P, Cardozo L, Fall M, Griffiths D, Rosier P, Ulmsten U, Van Kerrebroeck P, Victor A, Wein A (2002) The standardisation of terminology of lower urinary tract function: report from the Standardisation Subcommittee of the International Continence Society. Neurourol Urodyn 21:167-178

2. Jha S, Ammenbal M, Metwally M (2012) Impact of incontinence surgery on sexual function: a systematic review and meta-analysis. J Sex Med 9:34-43

3. Simsek A, Kirecci SL, Bayar G, Horasanli K, Ozgor F, Gurbuz ZG (2017) Evaluation of per-operative cough stress test during transobturator midurethral sling surgery. Arch Ital Urol Androl 89:222-225

4. Shin YS, You JH, On JW, Kim MK (2018) Clinical significance of anatomical urethral length on stress urinary incontinence women. Int J Womens Health 10:337-340
5. Athanasopoulos A, Perimenis P, Giannitsas K, Markou S, Gyftopoulos K, Fisfis J, Liatsikos E, Barbalias G (2005) The relationship between the perineal length measurements and the urodynamic stress incontinence. Int Urol Nephrol 37:701-705

6. Thankamony A, Ong K, Dunger D, Acerini C, Hughes I (2009) Anogenital distance from birth to two years: a population study. Environ Health Perspect 117:1786-1790

7. Sánchez-Ferrer ML, Prieto-Sánchez MT, Moya-Jiménez C, Mendiola J, García-Hernández CM, Carmona-Barnosi A, Nieto A, Torres-Cantero AM (2018) Anogenital Distance and Perineal Measurements of the Pelvic Organ Prolapse (POP) Quantification System. J Vis Exp 139:57912

8. Sathyanarayana S, Beard L, Zhou C, Grady R (2010) Measurement and correlates of ano-genital distance in healthy, newborn infants. Int J Androl 33:317-323

9. Suzuki Y, Yoshinaga J, Mizumoto Y, Serizawa S, Shiraishi H (2012) Foetal exposure to phthalate esters and anogenital distance in malenewborns. Int J Androl 35:236-244

10. Bustamante-Montes LP, Hernández-Valero MA, Flores-Pimentel D et a (2013) Prenatal exposure to phthalates is associated with decreased anogenital distance and penile size in male newborns. J Dev Orig Health Dis 4:300-306

11. Mira-Escolano M-P, Mendiola J, Mínguez-Alarcón L et al (2014) Anogenital distance of women in relation to their mother's gynaecological characteristics before or during pregnancy. Reprod Biomed Online 28:209-215

12. Bump RC, Mattiasson A, Bø K et al (1996) The standardization of terminology of female pelvic organ prolapse and pelvic floor dysfunction. Am J Obstet Gynecol 175:10-17

13. Swan SH, Sathyanarayana S, Barrett ES et al (2015) First trimester phthalate exposure and anogenital distance in newborns. Hum Reprod 30:963-972

14. Hernández-Peñalver Al, Sánchez-Ferrer ML, Mendiola J, Adoamnei E, Prieto-Sánchez MT, Corbalán-Biyang S, Carmona-Barnosi A, Nieto A, Torres-Cantero AM (2018) Assessment of anogenital distance as a diagnostic tool in polycystic ovary syndrome. Reprod Biomed Online 37:741-749

15. Mendiola J, Sánchez-Ferrer ML, Jiménez-Velázquez R et al (2016) Endometriomas and deep infiltrating endometriosis in adulthood are strongly associated with anogenital distance, a biomarker for prenatal hormonal environment. Hum Reprod 31:2377-2383

16. Vakili B, Zheng YT, Loesch H, Echols KT, Franco N, Chesson RR (2005) Levator contraction strength and genital hiatus as risk factors for recurrent pelvic organ prolapse. Am J Obstet Gynecol 192:1592-1598

17. Lowder JL, Oliphant SS, Shepherd JP, Ghetti C, Sutkin G (2016) Genital hiatus size is associated with and predictive of apical vaginal support loss. Am J Obstet Gynecol 214(718):e1-8

\section{Publisher's Note}

Springer Nature remains neutral with regard to jurisdictional claims in published maps and institutional affiliations.

\section{Submit your manuscript to a SpringerOpen ${ }^{\circ}$ journal and benefit from:}

- Convenient online submission

- Rigorous peer review

- Open access: articles freely available online

- High visibility within the field

- Retaining the copyright to your article

Submit your next manuscript at springeropen.com 